10

\title{
Синтез и исследование люминесцентных свойств тантало-ниобата гадолиния, активированного тербием
}

\author{
() Г.А. Гусев ${ }^{1}$, С.М. Маслобоева ${ }^{2}$, М.А. Яговкина ${ }^{1}$, М.В. Заморянская ${ }^{1}$ \\ ${ }^{1}$ ФТИ им. А.Ф. Иофрфе РАН, \\ 194021 Санкт-Петербург, Россия \\ ${ }^{2}$ Институт химии и технологии редких элементов и минерального сырья им. И.В. Тананаева - обособленное \\ подразделение ФИЦ „Кольский научный центр Российской академии наук“, \\ 184209 Апатиты, Россия \\ e-mail: ggusev@mail.ioffe.ru
}

Поступила в редакцию 23.09.2021 г.

В окончательной редакции 23.09.2021 г.

Принята к публикации 05.10.2021 г.

Впервые были синтезированы тантало-ниобаты гадолиния, активированные тербием $\left(\left(\mathrm{Gd}_{1-x} \mathrm{~Tb}_{x}\right) \mathrm{Nb}_{y} \mathrm{Ta}_{1-y} \mathrm{O}_{4}\right)$. Синтез проводился жидкофазным методом. Все исследованные материалы имели основную кристаллическую модификацию $\mathrm{M} \mathrm{GdNbO}_{4}$. Содержание примесных фаз не превышало $2-5 \%$. Проведено исследование спектров фото- и катодолюминесценции. Концентрационное тушение люминесценции иона тербия для серии твердых растворов, содержащих тантал $\left(\left(\mathrm{Gd}_{1-x} \mathrm{~Tb}_{x}\right) \mathrm{Nb}_{0.9} \mathrm{Ta}_{0.1} \mathrm{O}_{4}\right)$, наступает раньше, чем для чистых ниобатов гадолиния $\left(\left(\mathrm{Gd}_{1-x} \mathrm{~Tb}_{x}\right) \mathrm{NbO}_{4}\right)$. Полученные материалы перспективны для использования в качестве сцинтилляторов.

Ключевые слова: тантало-ниобаты гадолиния, жидкофазный синтез, $\mathrm{Tb}^{3+}$, люминесценция, катодолюминесценция.

DOI: $10.21883 /$ OS.2022.02.51998.2759-21

\section{Введение}

Ниобаты $\left(\mathrm{LnNbO}_{4}\right)$ и танталаты $\left(\mathrm{LnTaO}_{4}\right)$ редкоземельных элементов, как активированные, так и неактивированные редкоземельными ионами (РЗИ), являются перспективными функциональными материалами. Эти вещества широко применяются в качестве люминофоров и лазерных кристаллов [1], детекторов рентгеновского излучения [2] и сцинтилляторов в телевизионных панелях [3]. Их использование обусловлено люминесцентными и фотоэлектронными свойствами, высокой физической и химической стойкостью [4].

Одним из важнейших свойств таких соединений является наличие полосы собственной люминесценции в синем диапазоне спектра. Она связана с комплексами $\mathrm{NbO}_{4}$ или $\mathrm{TaO}_{4}$ в ниобатах или танталатах соответственно [5]. Энергетические уровни этих комплексов могут сенсибилизировать люминесценцию излучательных центров, таких как РЗИ. Средний атомный номер вещества также является важным параметром для практического применения соединения в качестве сцинтиллятора [6]. Чем выше атомный номер, тем больше способность данного сцинтиллятора к поглощению высокоэнергетического излучения. В связи с этим особое внимание заслуживает ниобат гадолиния. Он обладает яркой собственной люминесценцией и более высоким средним атомным номером, чем, например, широко используемый ниобат иттрия. В то же время танталат гадолиния является одним из самых плотных известных сцинтилляторов. Однако он обладает существенно более слабым выходом собственной люминесценции по сравнению с $\mathrm{GdNbO}_{4}$ [7]. Поэтому кажется перспективным заместить часть ниобия в $\mathrm{GdNbO}_{4}$ танталом для того, чтобы повысить средний атомный номер вещества, но в то же время сохранить люминесцентные свойства ниобата гадолиния.

Твердые растворы тантало-ниобатов гадолиния исследовались в ряде работ [7,8]. Так, было показано, что промежуточный твердый раствор $\mathrm{GdNb}_{x} \mathrm{Ta}_{1-x} \mathrm{O}_{4}$ обладает более высоким выходом люминесценции по сравнению с $\mathrm{GdNbO}_{4}$ при пониженной температуре [7]. Также было продемонстрировано, что твердый раствор $\mathrm{GdTa}_{0.8} \mathrm{Nb}_{0.2} \mathrm{O}_{4}$ обладает значениями времен затухания с очень короткой доминирующей составляющей $\sim 17 \mathrm{~ns}$ [9]. Подобные свойства делают тантало-ниобат гадолиния перспективным сцинтиллятором.

Добавление РЗИ в ниобаты и танталаты рассматривалось в ряде публикаций [2,3,10-12]. Однако исследования активированных твердых растворов $\mathrm{GdNb}_{x} \mathrm{Ta}_{1-x} \mathrm{O}_{4}$ практически не встречаются. Было показано, что активация тантало-ниобата гадолиния европием дает материал с яркой красной люминесценцией. Такое вещество перспективно для применения в качестве детектора высокоэнергетического излучения [13]. В связи с этим интересным кажется реализация схемы дополнительной сенсибилизации европия тербием. Такая связка РЗИ широко используется в других материалах [14]. Кроме того, активация $\mathrm{GdNb}_{x} \mathrm{Ta}_{1-x} \mathrm{O}_{4}$ тербием может дать материал с яркой зеленой люминесценцией, который 
сам по себе способен представлять практический интерес. Такое соединение ранее не синтезировалось, и его люминесцентные свойства не изучались.

Самым широко применяемым методом получения ниобатов, танталатов и их твердых растворов является твердофазный синтез [9]. Однако при данном подходе присутствуют потери на этапе механического измельчения компонентов, и применяется длительный отжиг при температурах от $1400^{\circ} \mathrm{C}$. В настоящей работе использовался метод на основе жидкофазного синтеза тантало-ниобатов редкоземельных элементов $[13,15]$. Он позволил гомогенизировать компоненты на молекулярном уровне, а значит, более точно следовать заданному составу. Кроме того, используемые при таком методе температуры не превышают $1400^{\circ} \mathrm{C}$.

Целью настоящей работы являлся синтез и исследование структурных, люминесцентных свойств керамики тантало-ниобата гадолиния, активированного тербием перспективного сцинтилляционного материала.

\section{Материалы и методы исследования}

В настоящей работе исследовались образцы керамики $\left(\mathrm{Gd}_{1-x} \mathrm{~Tb}_{x}\right) \mathrm{Nb}_{y} \mathrm{Ta}_{1-y} \mathrm{O}_{4}$, где $x=0.05-0.2 ; y=0.9,1$. Порошки для получения этой керамики были синтезированы методом на основе жидкофазного синтеза $[13,16]$.

Для проведения синтеза использовались высокочистые фторидные ниобий- и тантал-содержащие растворы, которые были получены растворением оксидов $\mathrm{Nb}_{2} \mathrm{O}_{5}$ (ос.ч.) и $\mathrm{Ta}_{2} \mathrm{O}_{5}$ (ос.ч.) в $\mathrm{HF}$ (ос.ч.). Состав растворов соответствовал (в единицах $\mathrm{g} \cdot 1^{-1}$ ): $\mathrm{Nb}_{2} \mathrm{O}_{5}-146.0$, $\mathrm{F}^{-}-132.7 ; \mathrm{Ta}_{2} \mathrm{O}_{5}-109.3, \mathrm{~F}^{-}-105.0$. При получении тантало-ниобатов растворы $\mathrm{Nb}$ и Та смешивались между собой в объемах, обеспечивающих заданный состав исследуемых образцов. В Nb-, Та-содержащие растворы или их смеси вводился 25\%-ный раствор $\mathrm{NH}_{4} \mathrm{OH}$ (ос.ч.), и проводилось осаждение гидроксидов ниобия и тантала до $\mathrm{pH} \sim 9-10$. Осадок отфильтровывался на нутч-фильтре и далее репульпацией трехкратно промывался деионизированной водой от ионов аммония и фтора при соотношении твердой и жидкой фаз $1: 3$. Подсушенный до влажности 60-70\% при $90^{\circ} \mathrm{C}$ остаток смешивался с растворами $\mathrm{Gd}\left(\mathrm{NO}_{3}\right)_{3}$ и $\mathrm{Tb}\left(\mathrm{NO}_{3}\right)_{3}$, объемы которых рассчитывались исходя из заданного содержания $\mathrm{Gd}$ и $\mathrm{Tb}$ в образцах. Растворы $\mathrm{Gd}\left(\mathrm{NO}_{3}\right)_{3}$, $\mathrm{Tb}\left(\mathrm{NO}_{3}\right)_{3}$ заданной концентрации были приготовлены растворением соответствующих оксидов $\mathrm{Gd}_{2} \mathrm{O}_{3}, \mathrm{~Tb}_{4} \mathrm{O}_{7}$ в $\mathrm{HNO}_{3}$ (ос.ч.). При растворении $\mathrm{Tb}_{4} \mathrm{O}_{7}$ также добавлялась перекись водорода $\mathrm{H}_{2} \mathrm{O}_{2}$ (ос.ч.). Полученная смесь перемешивалась в течение $3 \mathrm{~h}$, и в образовавшуюся пульпу вводился 25\%-ный раствор $\mathrm{NH}_{4} \mathrm{OH}$ до $\mathrm{pH} \sim 10$. Остаток отфильтровывался, промывался деионизированной водой при соотношении твердой и жидкой фаз $1: 3$, сушился при $\sim 150^{\circ} \mathrm{C}$ и прокаливался при $700^{\circ} \mathrm{C}$ в течение $4 \mathrm{~h}$. Затем порошки размалывались в шаровой халцедоновой мельнице МК 1 и прокаливались в электропечи КЭП14/1400П в течение $4 \mathrm{~h}$ при $\sim 1200^{\circ} \mathrm{C}$.

Во фторидных $\mathrm{Nb}$ - и Та-содержащих растворах содержание ниобия и тантала определялось гравиметрическим методом, фторид-ионов - потенциометрическим на иономере ЭВ-74 с F-селективным электродом ЭВЛ-1М3. Фтор в синтезированных порошках анализировали методом пирогидролиза. $\mathrm{Gd}$ и $\mathrm{Tb}$ в фильтратах и промывных растворах определяли методом атомно-эмиссионной спектрометрии (АЭС-ИСП) на спектрометре ICPE 9000, Shimadzu.

Данные АЭС-ИСП показали, что в фильтратах и промывных растворах концентрации Gd $\left(1-3 \cdot 10^{-5} \mathrm{~g} / 1\right)$, $\mathrm{Tb}\left(<1 \cdot 10^{-4} \mathrm{~g} / \mathrm{l}\right)$ составляли следовые количества. Следовательно, $\mathrm{Gd}$ и $\mathrm{Tb}$ практически полностью перешли из растворов $\mathrm{Gd}\left(\mathrm{NO}_{3}\right)_{3}$ и $\mathrm{Tb}\left(\mathrm{NO}_{3}\right)_{3}$ в гидроксидный осадок при выбранных условиях. Концентрация фтора в порошках находилась ниже предела чувствительности используемого метода анализа (менее $1 \cdot 10^{-3} \%$ ).

Керамические образцы в форме таблеток диаметром 5-10 cm спрессовывались из полученного порошка при давлении около $3.8 \mathrm{~kg} / \mathrm{cm}^{2}$. В качестве связующего использовался поливиниловый спирт. После прессования таблетки выдерживались в электропечи КЭП 14/1400П при $1380^{\circ} \mathrm{C}$ в течение $3 \mathrm{~h}$.

Элементный состав образцов исследовался методом рентгеноспектрального микроанализа (РСМА) на электронно-зондовом микроанализаторе Camebax, оснащенном четырьмя спектрометрами рентгеновского диапазона. В качестве эталонов использовались фосфаты редкоземельных элементов $\mathrm{GdPO}_{4}, \mathrm{TbPO}_{4}$ и металлы $\mathrm{Nb}$ и Та (с чистотой 99.9\%). Для анализа использовались следующие аналитические линии: $\mathrm{Gd}-\mathrm{L} \alpha, \mathrm{Tb}-\mathrm{L} \alpha$, $\mathrm{Ta}-\mathrm{M} \alpha, \mathrm{Nb}-\mathrm{L} \alpha$. Содержание кислорода в твердом растворе рассчитывалось по стехиометрии. Анализ был проведен в 8-12 случайных областях каждого образца. При этом ускоряющее напряжение электронов равнялось $20 \mathrm{kV}$, поглощенный ток $I=5-10 \mathrm{nA}$. Диаметр электронного пучка составлял $\sim 5 \mu \mathrm{m}$.

Фазовый состав полученных образцов исследовался методом рентгендифракционного фазового анализа (РДФА) на дифрактометре D2 Phaser (Bruker, Germany) (медная трубка, $\lambda=1.5406 \AA$, ускоряющие ток и напряжение - $10 \mathrm{~mA}$ и $30 \mathrm{kV})$, оборудованном PSD-детектором. Расшифровка фазового состава выполнялась с помощью программного пакета Eva (Bruker), опираясь на базу данных ICDD (PDF 2, relies 2014).

Спектры фотолюминесценции были получены с помощью спектрофлуориметра Fluorolog-3 „Horiba“ при длине волны возбуждения $260 \mathrm{~nm}$. Также люминесцентные свойства материалов исследовались методом локальной катодолюминесценции (КЛ) на той же установке Camebax, на которой выполнялся РСМА. Такое совмещение позволяло исследовать люминесценцию и элементный состав одного и того же микрообъема образца. Ускоряющее напряжение при получении КЛ-спектров и времен затухания $(\tau)$ интенсивности люминесценции 
составляло $20 \mathrm{kV}$, поглощенный ток - $10 \mathrm{nA}$, диаметр электронного зонда $-2 \mu \mathrm{m}$. Измерения кинетики полос КЛ проводилось в режиме отклонения электронного пучка.

При выполнении исследований на электроннозондовом микроанализаторе Camebax все образцы фиксировались в измерительных кассетах с помощью сплава Розе. Для обеспечения стекания заряда с поверхности материала во время облучения электронным пучком на поверхность образцов дополнительно наносилась углеродная пленка на универсальном вакуумном посте JEE-4C.

\section{Результаты и обсуждение}

\section{Элементный и фазовый состав}

РСМА показал соответствие измеренного среднего элементного состава образцов заданному практически для всех образцов в пределах ошибки используемого метода (таблица). Однако для образца Nb0.15 относи-

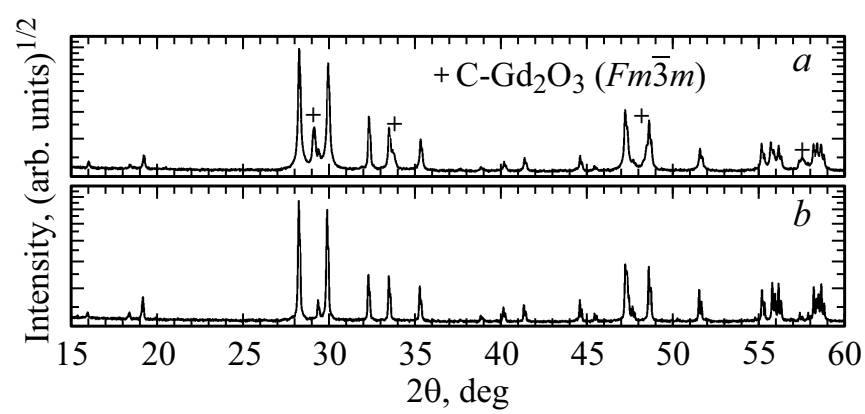

Pис. 1. Дифрактограммы керамических образцов $(\lambda=1.5406 \AA$, ускоряющие ток и напряжение $-10 \mathrm{~mA}$ и $30 \mathrm{kV}):(a)$ образец $\left(\mathrm{Gd}_{0.95} \mathrm{~Tb}_{0.05}\right) \mathrm{Nb}_{0.9} \mathrm{Ta}_{0.1} \mathrm{O}_{4} \quad(\mathrm{NbTa} 0.05)$; (b) образец $\left(\mathrm{Gd}_{0.95} \mathrm{~Tb}_{0.05}\right) \mathrm{NbO}_{4}(\mathrm{Nb0.05})$.

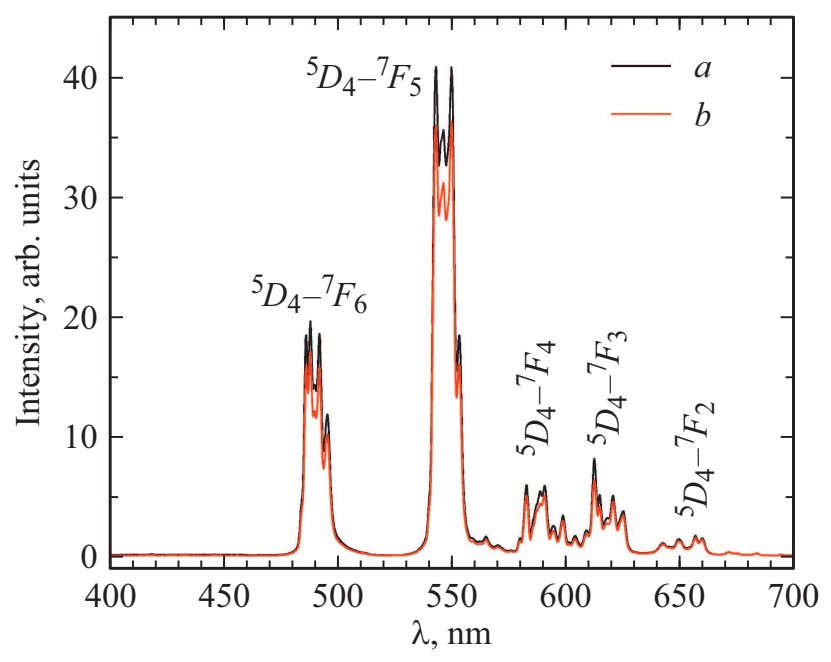

Рис. 2. Спектры фотолюминесценции керамики: (a) образец $\quad\left(\mathrm{Gd}_{0.95} \mathrm{~Tb}_{0.05}\right) \mathrm{Nb}_{0.9} \mathrm{Ta}_{0.1} \mathrm{O}_{4} \quad(\mathrm{NbTa} 0.05) ; \quad(b) \quad$ образец $\left(\mathrm{Gd}_{0.95} \mathrm{~Tb}_{0.05}\right) \mathrm{NbO}_{4}(\mathrm{Nb0.05})$.
Элементный состав керамических образцов $\left(\mathrm{Gd}_{1-x} \mathrm{~Tb}_{x}\right) \mathrm{Nb}_{y} \mathrm{Ta}_{1-y} \mathrm{O}_{4}$ по данным РCMA

\begin{tabular}{|c|c|c|c|}
\hline \multirow[t]{2}{*}{ Образец } & \multirow[t]{2}{*}{ Планируемый состав } & \multicolumn{2}{|c|}{$\begin{array}{l}\text { Содержание элемента } \\
\text { (PCMA), formula units }\end{array}$} \\
\hline & & $\mathrm{Tb}, x$ & $\mathrm{Nb}, y$ \\
\hline NbTa0.05 & $\left(\mathrm{Gd}_{0.95} \mathrm{~Tb}_{0.05}\right) \mathrm{Nb}_{0.9} \mathrm{Ta}_{0.1} \mathrm{O}_{4}$ & $0.052 \pm 0.004$ & $0.892 \pm 0.010$ \\
\hline NbTa0.1 & $\left(\mathrm{Gd}_{0.9} \mathrm{~Tb}_{0.1}\right) \mathrm{Nb}_{0.9} \mathrm{Ta}_{0.1} \mathrm{O}_{4}$ & $0.097 \pm 0.003$ & $0.908 \pm 0.010$ \\
\hline $\mathrm{NbTa} 0.15$ & $\left(\mathrm{Gd}_{0.85} \mathrm{~Tb}_{0.15}\right) \mathrm{Nb}_{0.9} \mathrm{Ta}_{0.1} \mathrm{O}_{4}$ & $0.149 \pm 0.004$ & $0.905 \pm 0.009$ \\
\hline $\mathrm{NbTa} 0.2$ & $\left(\mathrm{Gd}_{0.8} \mathrm{~Tb}_{0.2}\right) \mathrm{Nb}_{0.9} \mathrm{Ta}_{0.1} \mathrm{O}_{4}$ & $0.188 \pm 0.004$ & $0.902 \pm 0.006$ \\
\hline $\mathrm{Nb} 0.05$ & $\left(\mathrm{Gd}_{0.95} \mathrm{~Tb}_{0.05}\right) \mathrm{NbO}_{4}$ & $0.049 \pm 0.002$ & $0.999 \pm 0.004$ \\
\hline $\mathrm{Nb} 0.1$ & $\left(\mathrm{Gd}_{0.9} \mathrm{~Tb}_{0.1}\right) \mathrm{NbO}_{4}$ & $0.100 \pm 0.005$ & $0.996 \pm 0.004$ \\
\hline Nb0.15 & $\left(\mathrm{Gd}_{0.85} \mathrm{~Tb}_{0.15}\right) \mathrm{NbO}_{4}$ & $0.133 \pm 0.028$ & $0.996 \pm 0.002$ \\
\hline $\mathrm{Nb} 0.2$ & $\left(\mathrm{Gd}_{0.8} \mathrm{~Tb}_{0.2}\right) \mathrm{NbO}_{4}$ & $|0.193 \pm 0.009|$ & $1.000 \pm 0.001$ \\
\hline
\end{tabular}

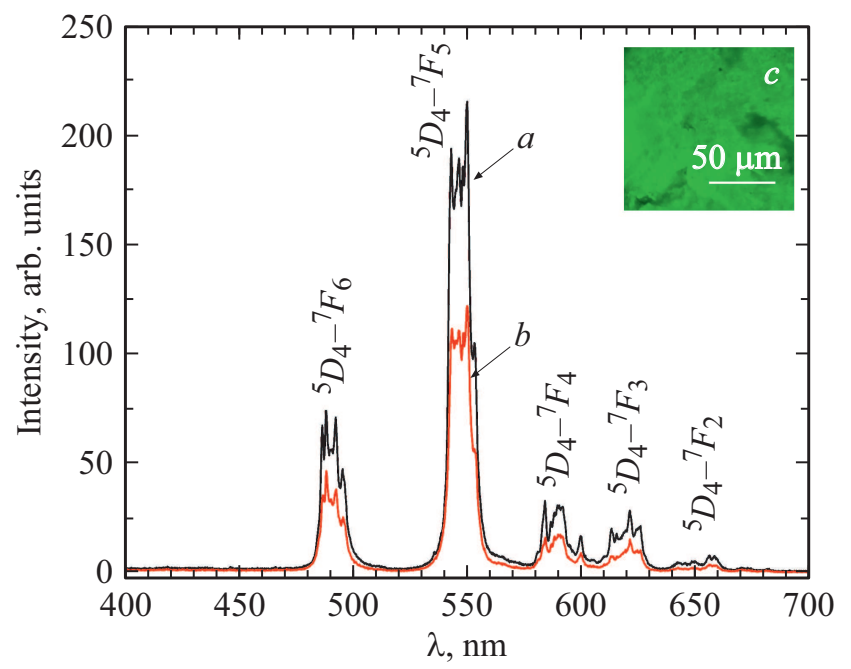

Рис. 3. Спектры КЛ керамики: (a) образец $\left(\mathrm{Gd}_{0.95} \mathrm{~Tb}_{0.05}\right) \mathrm{Nb}_{0.9} \mathrm{Ta}_{0.1} \mathrm{O}_{4} \quad(\mathrm{NbTa} 0.05) ; \quad(b) \quad$ образец

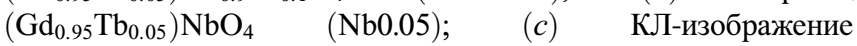
образца $\mathrm{Nb0.05.}$

тельное отклонение содержания Тb в случайных областях образца превышает ошибку метода (10\% для малых концентраций) и составляет $21 \%$. Это говорит о существенной неоднородности распределения активатора для данного образца.

Ниобаты гадолиния могут иметь две кристаллические модификации: тетрагональную Т (при высоких температурах) и низкотемпературную моноклинную $\mathrm{M}[1,5]$. Танталаты гадолиния (помимо упомянутых двух) имеют дополнительную модификацию - моноклинный политип М' с уменьшенным вдвое параметром решетки $b$ (относительно политипа М) [5]. Эта модификация реализуется при более низких температурах, чем модификация М [13]. По результатам РДФА все полученные образцы представляют собой $\mathrm{GdNbO}_{4}$ моноклинной сингонии с пространственной группой $I 2 / a$ (М-политип, PDF 01-075-5932). В образцах NbTa0.05, NbTa0.2, $\mathrm{Nb0.1}$ обнаружено незначительное количество примеси $\mathrm{Gd}_{2} \mathrm{O}_{3}$. Максимальное относительное содержание оксида 

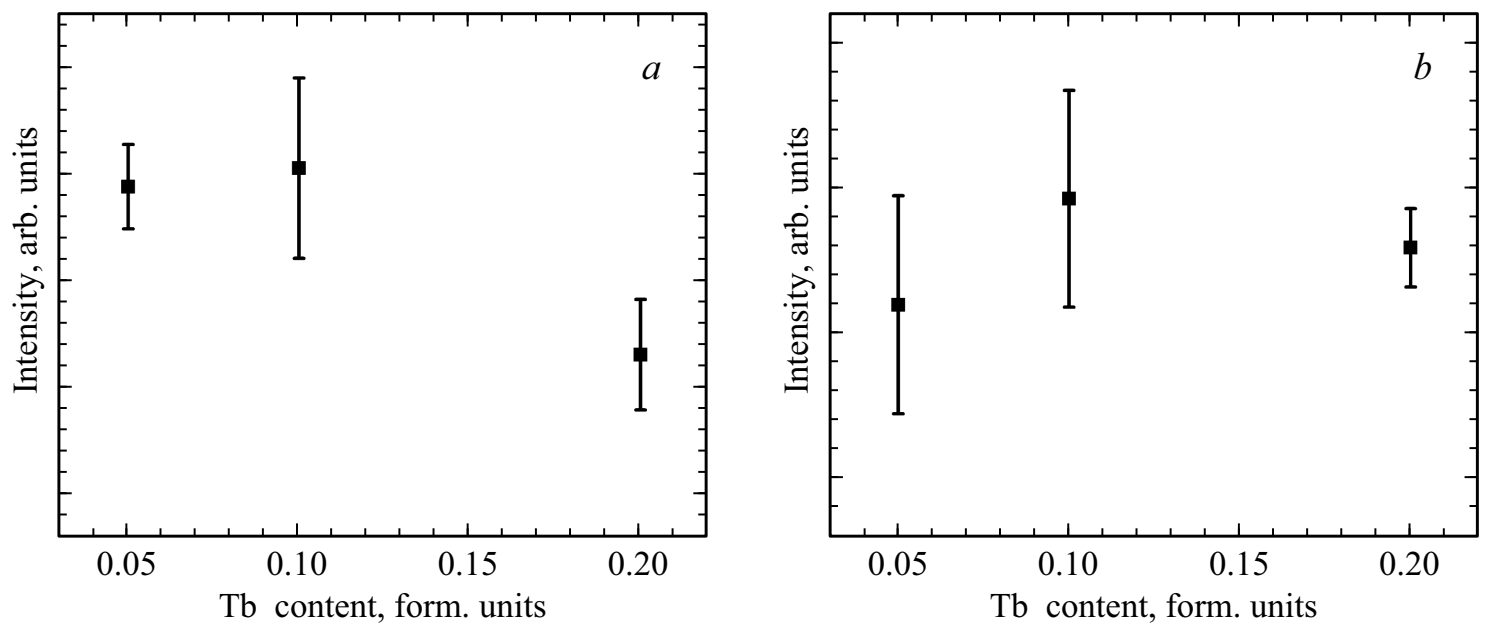

Рис. 4. Концентрационные зависимости интенсивности КЛ: (a) серия образцов $\left(\mathrm{Gd}_{1-x} \mathrm{~Tb}_{x}\right) \mathrm{Nb}_{0.9} \mathrm{Ta}_{0.1} \mathrm{O}_{4}\left(\mathrm{NbTa}_{0.05}-\mathrm{NbTa}_{0.2}\right)$; (b) серия образцов $\left(\mathrm{Gd}_{1-x} \mathrm{~Tb}_{x}\right) \mathrm{NbO}_{4}(\mathrm{Nb} 0.05-\mathrm{Nb} 0.2)$.
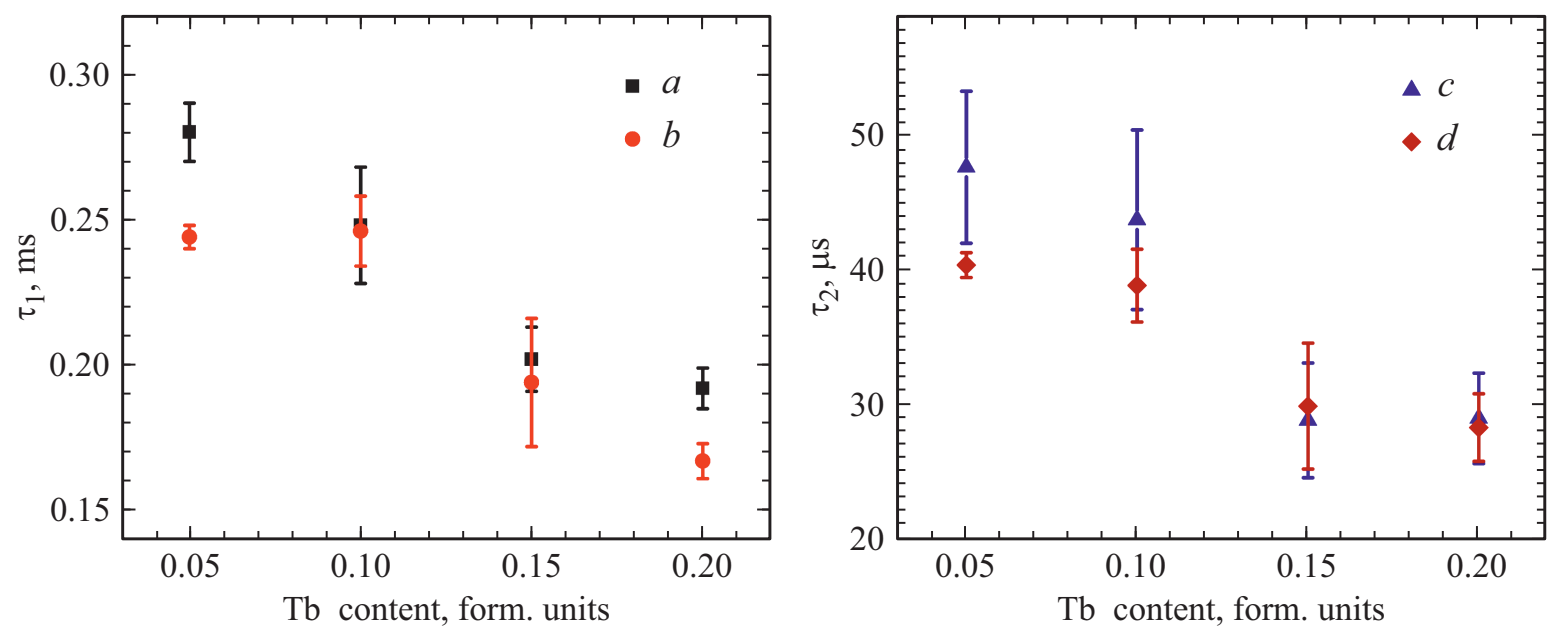

Рис. 5. Концентрационные зависимости времен затухания КЛ: $(a, c)$ серия образцов $\left(\mathrm{Gd}_{1-x} \mathrm{~Tb}_{x}\right) \mathrm{Nb}_{0.9} \mathrm{Ta}_{0.1} \mathrm{O}_{4}\left(\mathrm{NbTa}_{.05}-\mathrm{NbTa} 0.2\right)$; $(b, d)$ серия образцов $\left(\mathrm{Gd}_{1-x} \mathrm{~Tb}_{x}\right) \mathrm{NbO}_{4}(\mathrm{Nb} 0.05-\mathrm{Nb} 0.2)$.

гадолиния не превышает 5\% для образца $\mathrm{NbTa0} 05$ и $2-3 \%$ для образцов $\mathrm{NbTa} 0.2, \mathrm{Nb} 0.1$. Примесных фаз на основе тербия не обнаружено. Примеры полученных дифрактограмм представлены на рис. 1.

\section{Люминесцентные свойства}

Для двух образцов, с танталом в составе $\left(\mathrm{Gd}_{0.95} \mathrm{~Tb}_{0.05}\right) \mathrm{Nb}_{0.9} \mathrm{Ta}_{0.1} \mathrm{O}_{4} \quad(\mathrm{NbTa} 0.05) \quad$ и $\quad$ без $\quad$ тантала $\left(\mathrm{Gd}_{0.95} \mathrm{~Tb}_{0.05}\right) \mathrm{NbO}_{4} \quad(\mathrm{Nb0.05})$ были получены спектры фотолюминесценции (область размерами $1 \times 5 \mathrm{~mm}$, рис. 2). Из представленного рисунка видно, что форма спектров люминесценции идентична для обоих образцов.

Для всех полученных материалов также были получены спектры КЛ. Этот метод отличался большей локальностью (диаметр пучка электронов $\sim 2 \mu \mathrm{m}$ ). Примеры полученных спектров для образцов $\mathrm{NbTa0} 05$ и
$\mathrm{Nb0.05}$ представлены на рис. 3, $a, b$. На них можно наблюдать те же излучательные полосы, что и при фотовозбуждении. Расшифровка излучательных переходов на спектрах фотолюминесценции и КЛ производилась по литературным данным $[3,17,18]$. На графиках можно наблюдать полосы переходов с уровня ${ }^{5} D_{4}$ на уровни ${ }^{7} F_{j}(j=2-6)$. Переходы с уровня ${ }^{5} D_{3}$ не наблюдаются. Скорее всего, это связано с тушением излучения с этого уровня в результате кросс-релаксации возбуждения на уровень ${ }^{5} D_{4}[17,19]$. Полученные КЛ-изображения показали неоднородность интенсивности люминесценции в синтезированных образцах (пример КЛ-изображения рис. 3,c). Скорее всего, это связано с особенностями поверхностей исследуемой керамики, так как РСМА не показал существенной неоднородности распределения активатора для всех образцов, кроме Nb0.15. Из-за такой неоднородности достоверно определить какой из 


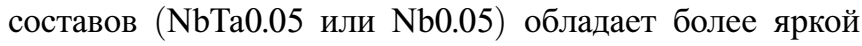
люминесценцией не удалось.

Для двух серий образцов $\left(\left(\mathrm{Gd}_{1-x} \mathrm{~Tb}_{x}\right) \mathrm{Nb}_{0.9} \mathrm{Ta}_{0.1} \mathrm{O}_{4}\right.$ и $\left.\left(\mathrm{Gd}_{1-x} \mathrm{~Tb}_{x}\right) \mathrm{NbO}_{4}\right)$ были получены концентрационные зависимости интенсивности люминесценции самого яркого перехода ${ }^{5} D_{4}-{ }^{7} F_{5}$ (рис. 4). При этом интенсивности образцов с содержанием тербия 0.15 form. units на рис. 4 не представлены в связи с тем, что они оказались существенно ниже ожидаемых. Цвет поверхности этих керамических образцов значительно темнее, чем у остальных серий. Однако РСМА и РДФА не выявили отклонений, способных привести к такому изменению внешнего вида. Причина такого отличия пока не установлена.

При достижении определенной концентрации активатора в матрице выход люминесценции должен начать уменьшаться. Это происходит в результате передачи энергии между соседними ионами активатора, что сопровождается ростом вероятности безызлучательной рекомбинации. Такое явление называется концентрационным тушением [20]. Из-за существенной неоднородности люминесценции в исследуемой керамике сделать определенный вывод о наличии тушения из рис. 4 затруднительно. Однако можно заметить уменьшение интенсивности люминесценции для образцов с содержанием $\mathrm{Tb}^{3+}$ равным 0.2 form. units. Для уточнения концентрации активатора, при котором начинается тушение, были получены концентрационные зависимости времен затухания КЛ для того же перехода ${ }^{5} D_{4}-{ }^{7} F_{5}$. При этом времена затухания представлены для всех образцов обоих серий. Все кривые затухания люминесценции после прекращения облучения образца электронным пучком содержали две компоненты. Наличие двух времен затухания можно объяснить влиянием поверхности зерен, из которых состоит керамика [21]. Концентрационные зависимости для каждой из компонент даны на рис. $5, a, b, c, d$. Из представленных кривых видно, что времена затухания уменьшаются с увеличением содержания активатора. Это говорит о наличии концентрационного тушения. При этом кривые для серии $\left(\mathrm{Gd}_{1-x} \mathrm{~Tb}_{x}\right) \mathrm{NbO}_{4}$ более пологие. Из полученных данных можно сделать вывод, что для образцов с присутствием тантала в составе тушение наступает раньше, чем для „чистого“ ниобата гадолиния. Однако для определения точного состава, при котором начинается явление концентрационного тушения, необходим синтез образцов с меньшим содержанием активатора $\mathrm{Tb}^{3+}$.

\section{Выводы}

Впервые синтезированы тантало-ниобаты гадолиния, активированные тербием $\left(\left(\mathrm{Gd}_{1-x} \mathrm{~Tb}_{x}\right) \mathrm{Nb}_{y} \mathrm{Ta}_{1-y} \mathrm{O}_{4}\right.$, где $x=0.05-0.2 ; y=0.9,1)$. Для синтеза использовался жидкофазный метод.

Полученные керамические образцы были исследованы методами рентгеноспектрального микроанализа, рентгендифракционного фазового анализа, фотолюминесцен- ции и КЛ. Практически все синтезированные материалы имели средний элементный состав, соответствующий запланированному. Все исследованные образцы имели основную фазу $\mathrm{M} \mathrm{GdNbO}_{4}$. Относительное содержание примесных фаз не превышало 2-5\%.

На полученных спектрах фотолюминесценции и КЛ можно наблюдать полосы переходов с уровня ${ }^{5} D_{4}$ на уровни ${ }^{7} F_{j} \quad(j=2-6)$. Установлено, что концентрационное тушение для серии с танталом в составе $\left(\left(\mathrm{Gd}_{1-x} \mathrm{~Tb}_{x}\right) \mathrm{Nb}_{0.9} \mathrm{Ta}_{0.1} \mathrm{O}_{4}\right)$ наступает раньше, чем для серии без тантала $\left(\left(\mathrm{Gd}_{1-x} \mathrm{~Tb}_{x}\right) \mathrm{NbO}_{4}\right)$. Для точного определения концентрации активатора, при котором начинается спад интенсивности люминесценции, необходим синтез тантало-ниобатов гадолиния с более низким содержанием тербия.

Полученные материалы обладают яркой зеленой люминесценцией и перспективны для использования в качестве сцинтилляторов.

\section{Благодарности}

Авторы выражают благодарность Е.А. Васильеву за помощь в получении спектров фотолюминесценции, а также Т.Б. Поповой за помощь в получении РСМА-данных. Работа выполнена с использованием оборудования Центра коллективного пользования „Материаловедение и диагностика в передовых технологиях“ при частичной финансовой поддержке Министерства образования и науки РФ (идентификатор проекта RFMEFI62119X0021).

\section{Финансирование работы}

Исследование выполнено при поддержке РФФИ в рамках научного проекта № 20-32-90088.

\section{Конфликт интересов}

Авторы заявляют, что у них нет конфликта интересов.

\section{Список литературы}

[1] S. Ding, H. Zhang, Q. Zhang, Y. Chen, R. Dou, F. Peng, W. Liu, D. Sun. J. Solid State Chem., 262, 87 (2018). DOI: $10.1016 /$ j.jssc.2018.03.011

[2] B. Liu, K. Han, X. Liu, M. Gu, S. Huang, C. Ni, Z. Qi, G. Zhang. Solid State Commun., 144 (10-11), 484 (2017). DOI: 10.1016/j.ssc.2007.09.010

[3] X. Liu, C. Chen, S. Li, Y. Dai, H. Guo, X. Tang, Y. Xie, L. Yan. Inorg. Chem., 55 (20), 10383 (2016). DOI: 10.1021/acs.inorgchem.6b01637

[4] R. Dou, Q. Zhang, J. Gao, Y. Chen, S. Ding, F. Peng, W. Liu, D. Sun. Crystals, 8 (2), 55 (2018). DOI: $10.3390 /$ cryst 8020055

[5] H. Brunckova, H. Kolev, L.A. Rocha, E.J. Nassar, S.B. Moscardini, L. Medvecky. Appl. Surf. Sci., 504, 144358 (2020). DOI: 10.1016/j.apsusc.2019.144358 
[6] M.V. Nazarov, D.Y. Jeon, J.H. Kang, E.J. Popovici, L.E. Muresan, M.V. Zamoryanskaya, B.S. Tsukerblat. Solid State Commun., $131 \quad$ (5), $307 \quad$ (2004). DOI: $10.1016 /$ j.ssc.2004.05.025

[7] O. Voloshyna, O. Sidletskiy, D. Spassky, I. Gerasymov, I. Romet, A. Belsky. Opt. Mater., 76, 382 (2018). DOI: 10.1016/j.optmat.2018.01.003

[8] O.V. Voloshyna, I.A. Boiaryntseva, V.N. Baumer, A.I. Ivanov, M.V. Korjik, O.T. Sidletskiy. Nucl. Instrum. Methods Phys. Res., Sect. A., 764, 227 (2014). DOI: 10.1016/j.nima.2014.07.044

[9] O. Voloshyna, I. Gerasymov, O. Sidletskiy, D. Kurtsev, T. Gorbacheva, K. Hubenko, I. Boiaryntseva, A. Ivanov, D. Spassky, S. Omelkov, A. Belsky. Opt. Mater., 66, 332 (2017). DOI: 10.1016/j.optmat.2017.02.037

[10] R. Murakami, K. Kamada, S. Hatakeyama, K. Ueno, Y. Ueno, T. Tadokoro, Y. Shoji, S. Kurosawa, A. Yamaji, Y. Ohashi, M. Yoshino, Y. Yokota, A. Yoshikawa. Opt. Mater., 87, 94 (2019). DOI: 10.1016/j.optmat.2018.05.031

[11] M. Hirano, K. Ishikawa. J. Alloys Compd., 709, 64 (2017). DOI: $10.1016 /$ j.jallcom.2017.03.127

[12] S. Ding, Q. Zhang, J. Gao, J. Luo, W. Liu, X. Wang, G. Sun, D. Sun. Opt. Mater., 64, 474 (2017). DOI: 10.1016/j.optmat.2017.01.021

[13] Г.А. Гусев, С.М. Маслобоева, В.А. Кравец, М.А. Яговкина. Неорган. материалы, 57 (4), 404 (2021). DOI: 10.31857/S0002337X21040060 [G.A. Gusev, S.M. Masloboeva, V.A. Kravets, M.A. Yagovkina. Inorg. Mater., 57, 383 (2021). DOI: 10.1134/S0020168521040063]

[14] Z. Fu, X. Wang, Y. Yang, Z. Wu, D. Duan, X. Fu. Dalton Trans. 43 (7), 2819 (2014). DOI: 10.1039/C3DT52231H

[15] E.V. Ivanova, S.M. Masloboeva, V.A. Kravets, K.N. Orekhova, G.A. Gusev, A.N. Trofimov, O.B. Shcherbina, M.A. Yagovkina, A.A. Averin, M.V. Zamoryanskaya. Opt. Spectrosc., 127, 1011 (2019). DOI: 10.1134/S0030400X19120348

[16] G.A. Gusev, S.M. Masloboeva, M.V. Zamoryanskaya. J. Phys. Conf. Ser., 1697, 012154 (2020). DOI: $10.1088 / 1742-6596 / 1697 / 1 / 012154$

[17] M.J.J. Lammers, G. Blasse. Mater. Res. Bull., 19 (6), 759 (1984). DOI: 10.1016/0025-5408(84)90033-3

[18] M. Gu, L. Zhu, X. Liu, S. Huang, B. Liu, C. Ni. J. Alloys Compd., 501 (2), 371 (2010). DOI: $10.1016 /$ j.jallcom.2010.04.109

[19] T.O. Sales, R.J. Amjad, C. Jacinto, M.R. Dousti. J. Lumin., 205, 282 (2019). DOI: 10.1016/j.jlumin.2018.09.031

[20] D.L. Dexter, J.H. Schulman. J. Chem. Phys., 22 (6), 1063 (1954). DOI: 10.1063/1.1740265

[21] G.A. Gusev, K.N. Orekhova, V.A. Kravets, A.I. Isakov, A.N. Trofimov, M.V. Zamoryanskaya. J. Lumin., 222, 117084 (2020). DOI: 10.1016/j.jlumin.2020.117084 